\title{
Carotid sinus hypersensitivity syncope: is there a possible alternative approach to pacemaker implantation in young patients?
}

\author{
Zefferino Palamà, Ermenegildo De Ruvo, Domenico Grieco, Alessio Borrelli, Luigi Sciarra, Leonardo Calò \\ Cardiology Unit, Policlinico Casilino, Rome, Italy
}

Adv Interv Cardiol 2017; 13, 2 (48): 184-185

DOI: https://doi.org/10.5114/pwki.2017.67993

Carotid sinus hypersensitivity (CSH) is frequently found in about one third of elderly patients with syncope and trauma, but it may also be a common finding in younger patients. Pacemaker implantation is recommended in patients with recurrent syncope once $\mathrm{CSH}$ has been recognised. Cardioneuroablation (CNA) has been reported as an effective treatment in cardioinhibitory syncope $[1,2]$. A few reports are currently available in neurally mediated syncope and functional atrioventricular block [3, 4], but no previous experiences are available in carotid sinus hypersensitivity syncope.

A 42-year-old female patient, with normal heart and no relevant medical history, was referred to our centre for recurrent CSH syncope. As the patient refused PM implantation, autonomic nervous system modulation through CNA was proposed. At the basic EP study normal atrioventricular conduction parameters (AH $68 \mathrm{~ms}$, HV $50 \mathrm{~ms}$ ) were documented; during CSM a sinus arrest of up to $5.4 \mathrm{~s}$ occurred. Electroanatomical mapping of the right atrium with identification of phrenic nerve course was performed (Figure $1 \mathrm{~A}$ ). Anterior right CNA $\left(35 \mathrm{~W}, 43^{\circ} \mathrm{C}\right.$, $2 \mathrm{~min}$ and $40 \mathrm{~s}$ of RF delivery) at the level of the septal aspect of the superior vena cava determined a shortening of the basal sinus cycle length (from 975 ms to $730 \mathrm{~ms}$ ). Vagal stimulation by manual CSM did not cause any pause. After $20 \mathrm{~min}$, a new CSM showed suprahisian atrioventricular block with normal HV (RR max of $2608 \mathrm{~ms}$ ) (Figure $1 \mathrm{~B})$. Inferior right CNA $\left(35 \mathrm{~W}, 43^{\circ} \mathrm{C}, 1 \mathrm{~min}\right.$ and $30 \mathrm{~S}$ of RF delivery) posterior to the coronary sinus ostium was performed, in a region previously reported to be involved in AV conduction neuromodulation (located between the inferior vena cava and the right/left atrium) [1-3]. At CSM after RF and after 30 min of observation no longer pathological pauses were documented (RR max $1.4 \mathrm{~s})$. Shorter AV conduction intervals were observed (AH $48 \mathrm{~ms}$, HV $50 \mathrm{~ms}$ ). At 6-month follow-up the patient is still asymptomatic for syncope and dizziness.

Ablation lesions were performed using an anatomical approach (without AF-Nest mapping); no pharmacological test was performed to confirm the denervation; only right atrial CNA was performed in order to minimize the risk of complications; a longer follow-up period is needed to confirm ablation results.

The CNA restricted to the right atrium, if properly standardized, could be an attractive and safer alternative to PM implantation to treat CSH syncope, especially in younger patients who are more vulnerable to mediumand long-term complications related to device implantation.

\section{Conflict of interest}

The authors declare no conflict of interest. 

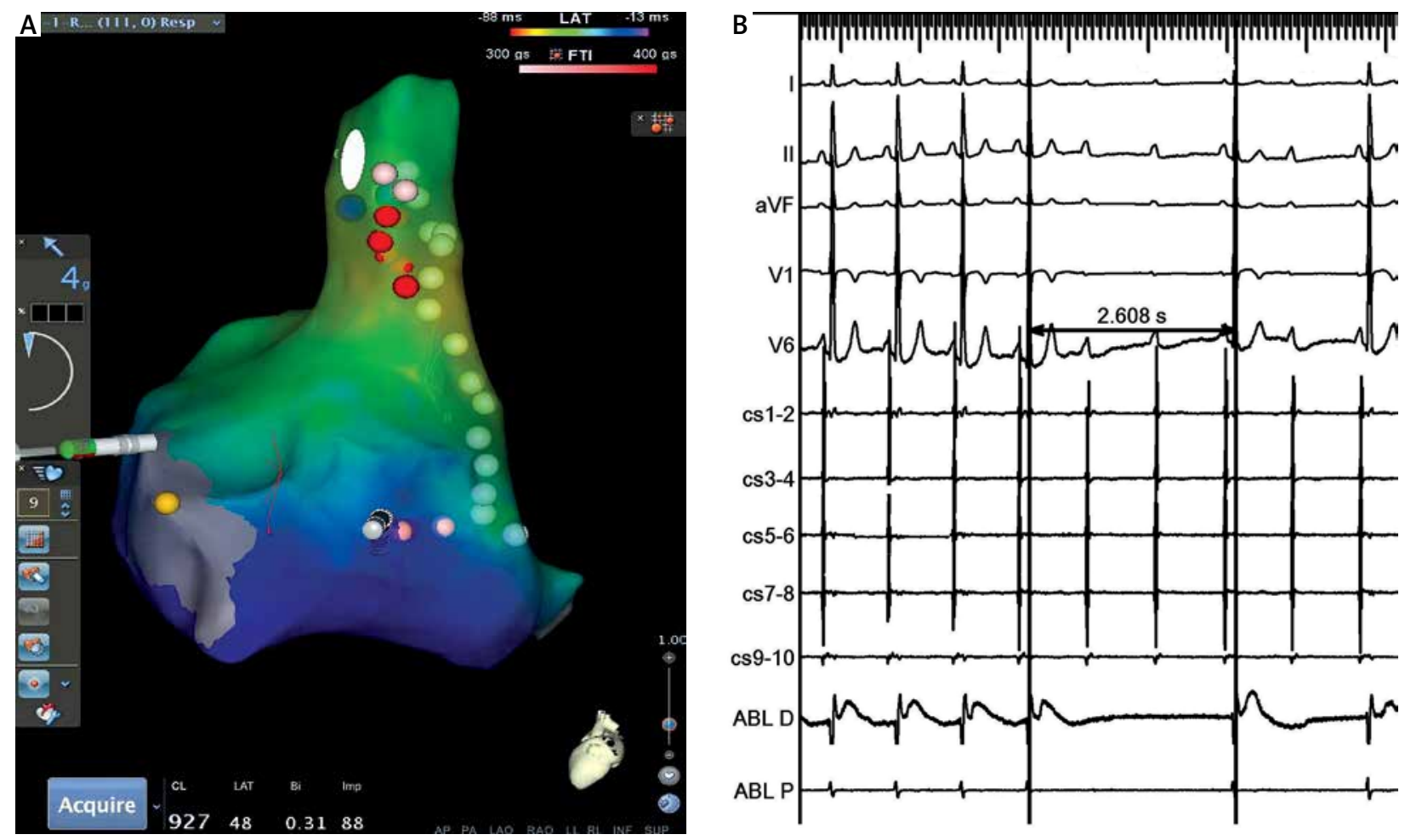

Figure 1. A - Electroanatomical map of the right atrium with identification of phrenic nerve course and lesions set, B - suprahissian atrioventricular block with normal HV after right anterior CNA

\section{References}

1. Pachon JC, Pachon EI, Pachon JC, et al. "CNA": new treatment for neurocardiogenic syncope, functional AV block and sinus dysfunction using catheter RF-ablation. Europace 2005; 7: 1-13.

2. Pachon JC, Pachon El, Cunha Pachon MZ, et al. Catheter ablation of severe neurally meditated reflex (neurocardiogenic or vasovagal) syncope: cardioneuroablation long-term results. Europace 2011 ; 13 : 1231-42.

3. Pachon MJC, Pachon M El, Lobo TJ, et al. Syncopal high-degree AV block treated with catheter RF ablation without pacemaker implantation. Pacing Clin Electrophysiol 2006; 29: 318-22.

4. Fukunaga $M$, Wichterle $D$, Peicl $P$, et al. Differential effect of ganglionic plexi ablation in a patient with neutrally mediated syncope and intermittent atrioventricular block. Europace 2017; 19: 119-26. 